\title{
Desempenho do Cultivar de Arroz bRS Pelota e Controle de CAPIM-ARroz (Echinochloa spp.) SUbMetidos a QUATRo ÉPOcAs de ENTRAda D'ÁGua APós APLICAÇÃo de Doses Reduzidas DE HERBICIDAS ${ }^{1}$
}

\author{
Performance of Rice Cultivar BRS Pelota and Control of (Echinochloa spp.) Submitted To Four \\ Flooding Times After Reduced Herbicide Dose Application
}

\begin{abstract}
ANDRES, A. ${ }^{2}$, FREITAS, G.D. ${ }^{3}$, CONCENÇO, G. ${ }^{4}$, MELO, P.T.B.S. ${ }^{5}$ e FERREIRA, F.A. ${ }^{6}$
RESUMO - Este trabalho teve como objetivo avaliar a possibilidade de reduzir as doses de herbicidas na lavoura de arroz irrigado, com a supressão das plantas daninhas pela antecipação da entrada da lâmina de água, bem como avaliar o controle de capim-arroz (Echinochloa spp.) em arroz irrigado, o desempenho da cultura e os efeitos dos herbicidas aplicados em pós-emergência sobre os atributos fisiológicos da cultura de arroz. O experimento foi conduzido em delineamento experimental de blocos ao acaso com parcelas subsubdivididas, com quatro repetições. As parcelas principais foram as entradas de água (A) aos 5, 10, 15 e 20 dias após aplicação dos herbicidas; as subparcelas, os herbicidas (H) bispyribac-sodium e bispyribac-sodium + clomazone; e as subsubparcelas, as doses de bispyribac-sodium (D) de 32, 40 e $48 \mathrm{~g} \mathrm{ha}^{-1}$ isoladas e em mistura com $300 \mathrm{~g} \mathrm{ha}^{-1}$ de clomazone. O bispyribac-sodium foi eficiente no controle de capim-arroz, com três folhas, quando a entrada de água ocorreu até cinco dias após a aspersão e/ou até o perfilhamento do arroz irrigado, quando em mistura com clomazone. É possivel trabalhar com doses inferiores à recomendada de bispyribac-sodium isoladamente, desde que a submersão seja imediata após a aplicação deste, ou até o perfilhamento quando em mistura com clomazone.
\end{abstract}

Palavras-chave: bispyribac-sodium, clomazone, doses, início da irrigação.

\begin{abstract}
The objectives of this work were to evaluate the possibility of reducing herbicide rates in flooded rice, using flooding as a tool to avoid weed emergence; to evaluate Echinochloa spp. control, culture establishment and growth and the effect of herbicides applied in pre-emergence on the physiological attributes of the rice culture. The experiment was conducted in a randomized block design with split-split plots, four floodings, two herbicides and three rates, with four replications. The plots were the floodings (A) 5, 10, 15 and 20 days after herbicide application and the split plots were the herbicides $(H)$ bispyribac-sodium and bispyribac-sodium + clomazone, and the split-split plots the herbicide rates (D), 32, 40 and $48 \mathrm{~g} \mathrm{ha}$ of bispyribac-sodium alone and in mixture with $300 \mathrm{~g} \mathrm{ha}^{-1}$ of clomazone. Bispyribac-sodium was efficient in controlling Echinochloa spp. plants up to the stage of three leaves, when flooding occurred in the field until 5 days after application, and/or until rice tillering started when mixed with clomazone. It is possible to work with rates of bispyribac-sodium alone below the recommended dosage if flooding starts immediately after application. When using the bispyribac-sodium and clomazone mixture, it is possible to start the flooding when the tillering process begins.
\end{abstract}

Keywords: bispyribac-sodium, clomazone, rates, flooding start.

Recebido para publicação em 1.11.2006 e na forma revisada em 25.10.2007.

2 Pesquisador da área de Matologia da Embrapa Clima Temperado, Caixa Postal 403, 96001-970, Capão do Leão-RS, <andre@cpact.embrapa.br>; ${ }^{3}$ Mestrando em Agronomia, Universidade Federal de Pelotas, Pelotas-RS, área de concentração em Produção Vegetal; ${ }^{4}$ Doutorando em Fitotecnia, Universidade Federal de Viçosa, Viçosa-MG; ${ }^{5}$ Doutor em Fitotecnia pela Universidade Federal de Pelotas, Capão do Leão-RS; ${ }^{6}$ Prof. Dr., Dep. de Fitotecnia da Universidade Federal de Viçosa, Viçosa-MG. 


\section{INTRODUÇÃO}

O principal método de controle de plantas daninhas do arroz no Rio Grande do Sul ainda é o químico, devido à facilidade, eficiência e economicidade (Erasmo et al., 2004). A aplicação dos herbicidas, dependendo das características do produto e da cultura, pode ser feita em pré-plantio incorporado (PPI), pré-emergência ou pós-emergência. Em alguns casos utilizam-se aplicações seqüenciais de produtos com diferentes mecanismos de ação, o que pode ser interessante, em razão do efeito de complementaridade dos produtos a fim de ampliar o espectro de ação da aplicação, controlar plantas emergidas e obter efeito residual até a entrada de água (Vieira et al., 2006).

O herbicida bispyribac-sodium em pósemergência é eficiente no controle de capimarroz (Echinochloa spp.), ciperáceas (Cyperus sp.), e angiquinho (Aeschynomene sp.), e o herbicida clomazone apresenta eficiência em pré-emergência de gramineas, principalmente capimarroz, milhã (Digittaria sp.) e papuã (Brachiaria plantaginea) (Concenço et a 1., 2006b). Em áreas com adequado manejo de irrigação, pode ser possivel controlar plantas daninhas em estádio de até quatro folhas com menores doses desses herbicidas (Andres \& Machado, 2004).

Avaliando o controle de capim-arroz em alta densidade e a produtividade de grãos de arroz em três épocas de irrigação, Andres \& Menezes (1997) verificaram que o atraso da irrigação após aplicação do herbicida pode diminuir o controle da planta daninha e a produtividade da cultura. Brito et al. (2001), avaliando a eficiência do herbicida bispyribac-sodium em mistura com clomazone no controle de plantas daninhas e seletividade à cultura do arroz irrigado, em duas épocas de entrada de água, concluíram que a mistura desses herbicidas possibilitou o retardo na entrada de água, com baixa reinfestação das plantas daninhas.

O manejo de água das áreas de arroz irrigado é essencial para adequada condução da lavoura, pois normalmente complementa o efeito dos herbicidas, propiciando melhor controle sobre plantas daninhas e maior disponibilidade inicial de nutrientes (Gomes et al., 1999). $\mathrm{O}$ efeito benéfico da lâmina de água sobre o controle de plantas daninhas é enfatizado por vários autores, como Balbinot Jr. et al. (2003), Concenço et al. (2006a) e Machado et al. (2006), que destacam a ação da água em termos de cobertura do solo e eliminação do oxigênio disponivel às raízes das plantas daninhas.

Em periodos em que a cultura do arroz encontra-se sem lâmina de água, ocorre a reinfestação da área, que conseqüentemente afeta a produtividade da cultura (Avila et al., 2000; Noldin et al., 2001). Eberhardt (1997) e Noldin et al. (2004) afirmaram que a presença constante da lâmina de água é método importante de controle de plantas daninhas no sistema pré-germinado, especialmente as poáceas. Solos drenados ou com lâmina de água baixa favorecem a competição de espécies mesofiticas.

O momento ideal de início de irrigação ocorre quando os aspectos ligados a otimização do uso da água, qualidade ambiental, custo da energia, controle de plantas daninhas e ecofisiologia da cultura conflitam entre si. Os efeitos benéficos da submersão do solo sobre as plantas de arroz - com exceção do controle das plantas daninhas e da função termorreguladora - pode ser obtido pela manutenção do solo saturado (Gomes et al., 1999). Entretanto, na prática, é quase impossivel manter o solo saturado em condições de lavoura. O manejo adequado da lâmina de água deve levar em conta o período mínimo de submersão do solo que não afete a produtividade de grãos.

Este trabalho teve como objetivo avaliar a possibilidade de reduzir as doses de herbicidas na lavoura de arroz irrigado, com a supressão das plantas daninhas pela antecipação da entrada da lâmina de água, bem como o controle de capim-arroz (Echinochloa spp.) em arroz irrigado, o desempenho da cultura e os efeitos dos herbicidas aplicados em pós-emergência sobre os atributos fisiológicos da cultura de arroz.

\section{MATERIAL E MÉTODOS}

O experimento foi realizado em condições de campo, no ano agrícola 2001/02. Utilizaram-se parcelas de $2 \times 5,5 \mathrm{~m}$, totalizando $11 \mathrm{~m}^{2}$. Utilizou-se o delineamento experimental de blocos ao acaso com parcelas subsubdivididas. As parcelas foram as entradas de água (A) aos $5,10,15$ e 20 dias após aplicação dos herbicidas; as subparcelas, os herbicidas $(\mathrm{H})$ bispyribac- 
sodium e clomazone; e as subsubparcelas, as doses de bispyribac-sodium (D) isoladas ou acrescidas de $300 \mathrm{~g} \mathrm{ha}^{-1}$ de clomazone. As épocas de entrada de água de 5, 10, 15 e 20 dias após a aplicação dos herbicidas (DAA) corresponderam aos estádios de desenvolvimento de arroz de três folhas, quatro folhas, início do perfilhamento e quatro perfilhos, respectivamente.

A área onde foi instalado o experimento foi cultivada nos últimos anos com arroz, apresentando população elevada de plantas daninhas, principalmente capim-arroz (Echinochloa spp.). O preparo do solo foi realizado em 1/11/2001 com uma aração e duas gradagens, seguido de duas passadas de rolo. A semeadura foi realizada no sistema convencional de cultivo, no dia 21/11/2001, com o cultivar BRS Pelota na densidade de $150 \mathrm{~kg} \mathrm{ha}^{-1}$, utilizando semeadora-adubadora SHM-1113 de 11 linhas espaçadas entre si em $17,5 \mathrm{~cm}$, em solo corrigido. A adubação foi realizada no momento da semeadura, conforme recomendações da ROLAS (1995).

Doze dias após a emergência da cultura do arroz (DAE), aplicaram-se os herbicidas no início da manhã, com vento em torno de $5 \mathrm{~km} \mathrm{~h}^{-1}$, umidade relativa do ar (UR) ao redor de $75 \%$ e temperatura de $25^{\circ} \mathrm{C}$. Utilizou-se equipamento de pressão constante propelido por $\mathrm{CO}_{2}$ com barra munida de quatro bicos Teejet 110.015 tipo leque $\left(110^{\circ}\right.$ de abertura do leque do jato e vazão constante de $150 \mathrm{~L} \mathrm{ha}^{-1}$ ) espaçados em $50 \mathrm{~cm}$. O capim-arroz encontrava-se com três a quatro folhas no momento da aplicação dos tratamentos.

As variáveis analisadas foram: área foliar, fitomassa seca e altura das plantas de arroz, todas realizadas em três estádios de desenvolvimento da cultura durante o ciclo, aos 40, 70 e 100 DAE (perfilhamento, pré-florescimento, pré-colheita). Realizou-se também avaliação visual de controle de capim-arroz aos 30, 45, 60 e 90 DAE, contagem do número de colmos de capim-arroz (Echinochloa spp.) por metro quadrado aos $95 \mathrm{DAE}$, número de colmos e panículas de arroz por metro linear aos 100 DAE e rendimento de grãos da cultura. Os dados foram submetidos à análise de variância pelo teste $\mathrm{F}$ a $5 \%$ de probabilidade. Em caso de significância estatística, foi realizada análise de regressão linear a $5 \%$. Os dados foram analisados de acordo com a significância das interações no teste F; somente interações significativas foram apresentadas.

Para análise da área foliar das plantas de arroz coletaram-se amostras de um metro linear, em cada parcela, para cada época de avaliação. Foram coletadas a terceira, sexta e nona linhas, para a primeira, segunda e terceira avaliações, respectivamente. A cada avaliação deixaram-se duas linhas e $0,5 \mathrm{~m}$ do início da parcela, consideradas bordaduras. Para manutenção do estado hídrico das folhas, as amostras foram acondicionadas em sacos plásticos contendo pedaço de algodão embebido em água, acondicionados em caixa de poliestireno expandido, e levadas até o laboratório, onde foram mantidas sob refrigeração até a realização da análise. A determinação foi realizada utilizando-se medidor fotoelétrico de área foliar, sendo medidas todas as folhas das plantas; o resultado foi obtido $\mathrm{em}^{2}$ de folha.

Quanto à análise de fitomassa seca, utilizaram-se as mesmas amostras da área foliar, que, depois de avaliadas, foram acondicionadas em sacos de papel e levadas à estufa de circulação forçada de ar a $65^{\circ} \mathrm{C}$ até peso constante, que foi alcançado aproximadamente em cinco dias.

A altura das plantas de arroz foi obtida com a utilização de régua, sendo avaliadas dez plantas aleatoriamente por parcela, evitando as linhas de bordadura. Considerou-se como altura da planta a altura do solo até a extremidade da folha-bandeira. A altura média da parcela foi obtida pela média das dez plantas. A avaliação de controle de capim-arroz pelo método visual foi realizada por três técnicos, sendo a nota final composta pela média aritmética. Utilizou-se a escala percentual, em que 0 (zero) representou ausência de controle e 100 o controle total de capim-arroz.

A contagem de colmos de capim-arroz foi realizada em área de $1 \mathrm{~m}^{2}$ por parcela, na parte reservada à colheita de grãos. Para determinação do número de colmos e panículas de arroz por metro linear, foram utilizadas as amostras de plantas usadas na terceira avaliação de área foliar. Foram contados os colmos e as panículas presentes nas amostras, no laboratório, antes da retirada das folhas. Para determinação do rendimento de grãos, coletouse amostra de $2 \mathrm{~m}^{2}$ em cada parcela, que foram 
encaminhadas ao secador até atingir valores próximos de $13 \%$ de umidade. Os dados foram transformados em kg de grãos por hectare.

\section{RESULTADOS E DISCUSSÃO}

Os resultados deste trabalho evidenciaram interferência da época de entrada de água na eficiência dos herbicidas para controle de capim-arroz e em algumas variáveis relacionadas ao desenvolvimento das plantas de arroz, que serão discutidas a seguir.

A área foliar evidenciou significância estatística para dose (D), herbicida (H) e interação época de entrada de água e herbicida (A x H). Observou-se que a mistura bispyribac-sodium + clomazone proporcionou os melhores índices de área foliar da cultura do arroz em todas as épocas de entrada de água após aplicação dos herbicidas (Figura 1). Houve acréscimo linear na área foliar das plantas de arroz, com o incremento da dose de bispyribac-sodium, na média dos tratamentos, isolado ou em mistura de tanque (Figura 2). Mesmo na menor dose de bispyribac-sodium ocorreu acréscimo na área foliar em relação ao tratamento sem controle. O efeito residual do clomazone, provavelmente, contribuiu para menor competição das invasoras com a cultura por espaço, luz e nutrientes, proporcionando acréscimo na área foliar das plantas de arroz.

A fitomassa seca da parte aérea das plantas de arroz mostrou significância estatística

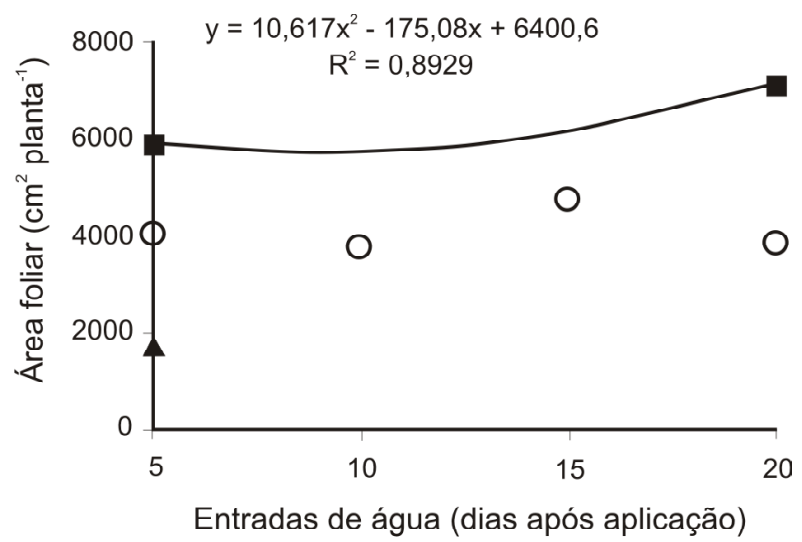

Figura 1 - Efeito do herbicida bispyribac-sodium isolado e em mistura com clomazone sobre a área foliar das plantas de arroz em função de diferentes épocas de entrada de água na lavoura. Média das doses. (o) bispyribac-sodium; ( bispyribac-sodium+clomazone; (A) Testemunha. para água $(\mathrm{A})$, herbicida $(\mathrm{H})$ e para a interação água/herbicida $(\mathrm{A} \times \mathrm{H})$. Na Figura 3 observase que o uso de bispyribac-sodium isolado provocou redução da fitomassa seca das plantas de arroz no retardamento da entrada de água; a irrigação aos 20 dias após aplicação dos herbicidas provocou redução de mais de $50 \%$ na fitomassa seca, quando comparado com o retardamento de cinco dias. Esse fato era esperado, pois em áreas aspergidas por herbicidas pós-emergentes, sem ação residual, como o bispyribac-sodium, a ausência da lâmina de água proporciona o rebrote de plantas ou nova emergência de plântulas. Quando a área foi inundada logo após a aplicação dos herbicidas, proporcionou comportamento similar para todas as doses de bispyribac-sodium, isolado ou em mistura com clomazone. Na Figura 4 observa-se aumento linear na matéria seca das plantas de arroz em relação ao aumento das doses de bispyribac-sodium, tanto isolada como em mistura (média). As respostas ao aumento de doses foram independentes da época de início da irrigação da lavoura.

A altura de plantas de arroz mostrou significância para (A), (H) e (A x D). Observou-se tendência à similaridade de resultados entre as doses de 80 e $100 \mathrm{~mL} \mathrm{ha}^{-1}$ de bispyribac-sodium, ao longo das épocas de entrada de água e também entre bispyribac-sodium e a mistura bispyribac-sodium+clomazone. A testemunha sempre se apresentou inferior aos demais tratamentos (Figura 5). Observou-se, também,



Figura 2 - Efeito das doses crescentes de bispyribac-sodium, isolado e em mistura, na área foliar das plantas de arroz. (ם) Tratamentos; (A) Testemunha. 
efeito da adição do herbicida clomazone ao bispyribac-sodium, em que os resultados obtidos com a mistura demonstraram ser superiores aos obtidos com o produto isolado (Figura 6).

O controle de capim-arroz foi influenciado por $(A),(H)$ e $(A \times H)$. Na primeira época de entrada de água (5 DAE) não se observaram diferenças entre os tratamentos. No entanto, com o retardo da entrada da água, provavelmente houve emergência de novas plântulas e/ou rebrote de capim-arroz nas parcelas com aspersão isolada de bispyribac-sodium. Com a adição de clomazone ocorreu o controle da reinfestação e do rebrote de capim-arroz,

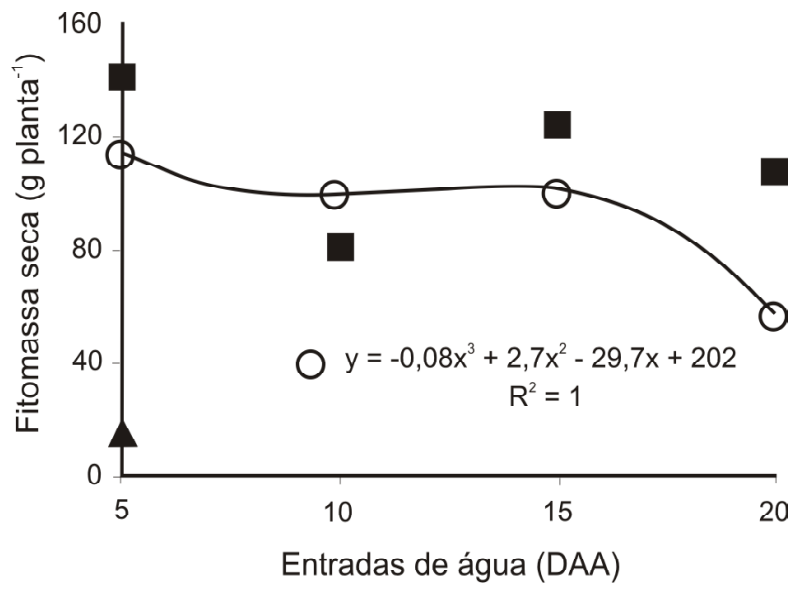

Figura 3 - Evolução de fitomassa seca das plantas de arroz em função de épocas de entrada de água na lavoura. (o) bispyribac-sodium; (ם) bispyribac-sodium+clomazone; (A) testemunha.

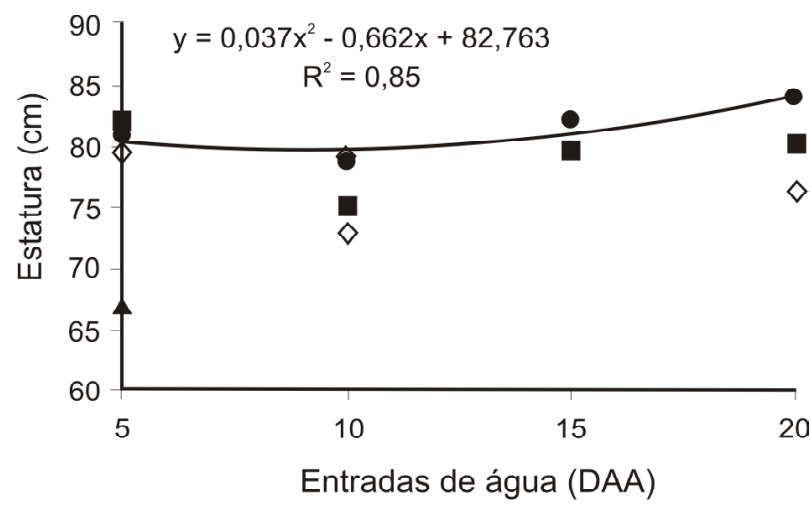

Figura 5 - Efeito de dose de bispyribac-sodium sobre a altura das plantas de arroz em função de diferentes épocas de entrada de água na lavoura (média de bispyribac-sodium isolado e em mistura com clomazone). ( $) 32 \mathrm{~mL} \mathrm{ha}^{-1}$; ( $40 \mathrm{~mL} \mathrm{ha}^{-1}$; (•) $48 \mathrm{~mL} \mathrm{ha}^{-1}$; (A) testemunha. proporcionando menor impacto negativo no controle com o atraso da irrigação. Na quarta época de início da irrigação (32 dias após a emergência - plantas de arroz com mais de quatro perfilhos), observou-se que mesmo a presença de clomazone não foi suficiente para evitar prejuízos no controle de capim-arroz (Figura 7). A mistura apresentou bons resultados até a terceira época de irrigação. No entanto, observa-se controle ineficiente na quarta época de entrada de água na lavoura (Figura 7).

O número de colmos de capim-arroz por metro quadrado foi influenciado por $(\mathrm{A}),(\mathrm{H}) \mathrm{e}$ $(\mathrm{A} \times \mathrm{H})$, se mantendo constante em todos os

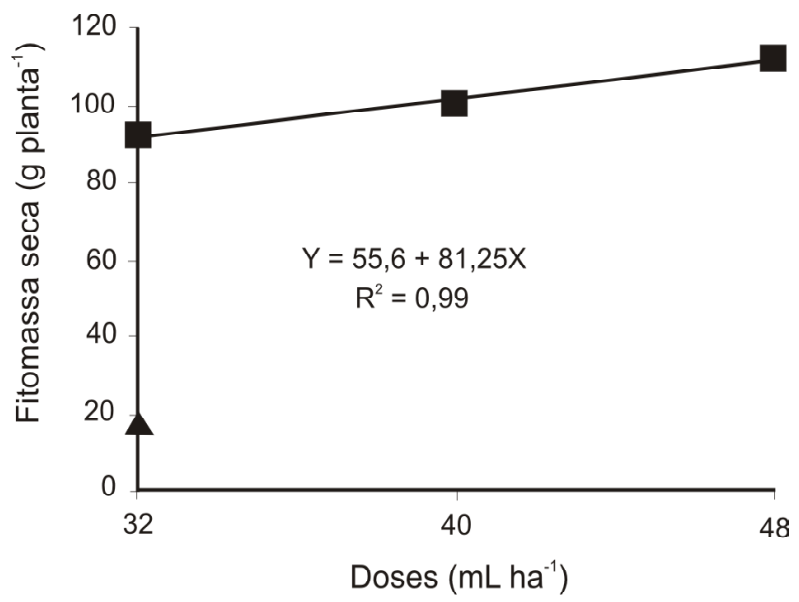

Figura 4 - Evolução da matéria seca das plantas de arroz em função de doses de bispyribac-sodium (isolado e em mistura). (ם) tratamentos; ( $\mathbf{\Delta})$ testemunha.

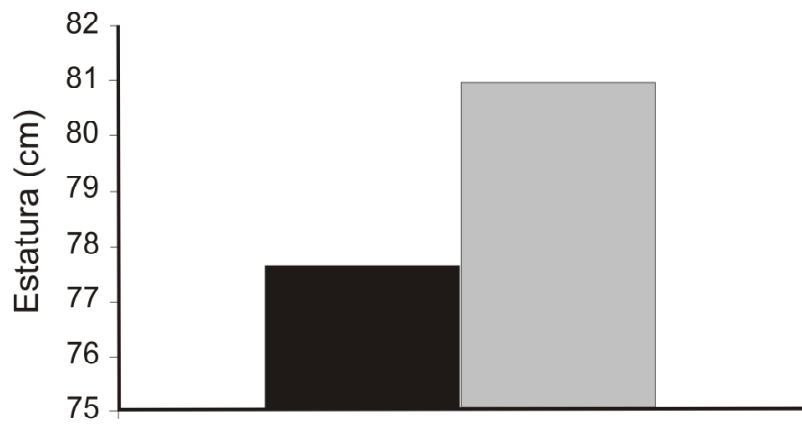

\section{Herbicidas}

Figura 6 - Efeito isolado dos herbicidas (bispyribac-sodium e bispyribac-sodium+clomazone), independentemente de doses e épocas de entrada de água na lavoura, sobre a altura das plantas de arroz. (目) bispyribac-sodium; ( $\square$ ) bispyribac-sodium + clomazone. 


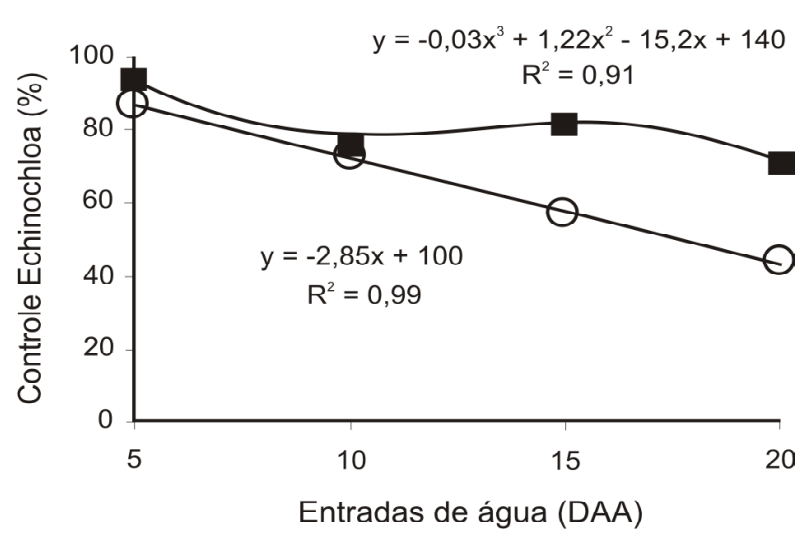

Figura 7 - Efeito isolado dos produtos (bispyribac-sodium e bispyribac-sodium+clomazone) sobre o controle de capimarroz em relação à época de entrada de água na lavoura. Média das doses. (o) bispyribac-sodium; ( $\square$ ) bispyribacsodium + clomazone.

tratamentos na primeira época. A partir da segunda época de entrada de água o número de plantas daninhas foi maior nos tratamentos de bispyribac-sodium isolado, evidenciando a necessidade de manejo eficiente da água, tanto em tempo (precoce) como na manutenção da lâmina de água. Foi possivel o ajuste de equação-resposta para bis pyribac-sodium, enquanto a mistura não apresentou diferenças significativas entre as épocas de início da irrigação (Figura 8). Os produtos em mistura apresentaram números, na média das doses por entrada de água, sempre inferiores aos tratamentos de bispyribac-sodium isolado. Esse efeito é particularmente visivel na terceira e quarta épocas de entrada de água.



Figura 8 - Número de colmos de capim-arroz por metro quadrado, independente de dose, em função de épocas de irrigação em arroz. Média de bispyribac-sodium isolado e em mistura com clomazone. (o) bispyribac-sodium; (a) bispyribac-sodium + clomazone; $(\boldsymbol{\Lambda})$ Testemunha.
O rendimento de grãos foi influenciado por (A), $(H),(D),(A \times H)$ e $(H \times D)$. O rendimento de grãos de arroz, corrigido para $13 \%$ de umidade, indica redução em todos os tratamentos com o atraso da entrada de água (Figura 9). Novamente os melhores resultados encontrados são dos tratamentos que envolveram a mistura de bispyribac-sodium + clomazone, em todas as épocas de irrigação. Em parcelas com aspersão de bispyribac-sodium isoladamente, o rendimento passou de $5,5 \mathrm{t} \mathrm{ha}^{-1}$ com entrada de água na área experimental aos 10 dias após a emergência-arroz com três folhas, para 2,0 $\mathrm{t} \mathrm{ha}^{-1}$ com irrigação aos 32 dias após a emergência - arroz com quatro perfilhos. Na mistura em tanque, esse decréscimo na produtividade foi menor, obtendo-se redução em torno de $1,1 \mathrm{t} \mathrm{ha}^{-1}$ com o atraso da irrigação. Em relação ao efeito de tratamentos herbicidas, observa-se similaridade quando a água entrou na lavoura logo após a aplicação (Figura 9).

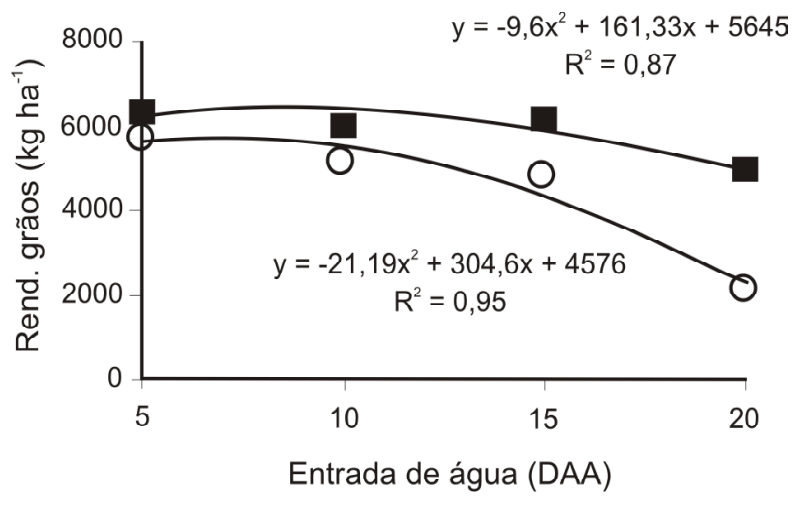

Figura 9 - Efeito herbicida (bispyribac-so dium e bispyribacsodium+clomazone) sobre o rendimento de grãos $\left(\mathrm{kg} \mathrm{ha}^{-1}\right)$ na cultivar de arroz irrigado BRS Pelota, em função de épocas de entrada de água. (o) bispyribac-sodium; (ם) bispyribac-sodium + clomazone; $(\boldsymbol{\Lambda})$ Testemunha.

Na média das épocas de irrigação, a maior dose de bispyribac-sodium isolado alcançou resultados similares ao da menor dose quando em mistura com clomazone (Figura 10). Considerando-se bispyribac-sodium isolado, o rendimento de grãos continuou crescendo até a maior dose, evidenciando o melhor controle na aspersão isolada de bispyribac-sodium, enquanto nos tratamentos com clomazone uma estabilização no aumento do rendimento foi alcançada com a utilização da dose intermediária. $\mathrm{Na}$ quarta época de irrigação, a menor dose de 


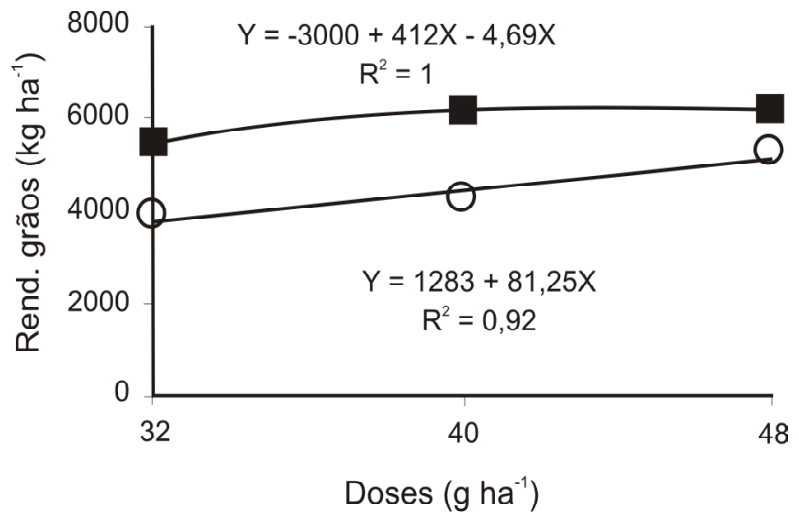

Figura 10 - Efeito de doses de bispyribac-sodium isolado ou em mistura com clomazone sobre o rendimento de grãos $\left(\mathrm{kg} \mathrm{ha}^{-1}\right)$ de arroz (média de quatro épocas de entrada de água após a aplicação dos herbicidas). (o) bispyribacsodium; ( $\mathbf{\square})$ bispyribac-sodium + clomazone.

bispyribac-sodium isolado apresentou valor próximo ao da testemunha sem controle.

O aumento nas doses de bispyribac-sodium (bispyribac-sodium) isolado ou em mistura com clomazone (clomazone) proporcionou acréscimo linear na área foliar (Figura 2). Essa maior disponibilidade de captação de energia solar possibilitou incremento na fitomassa seca (Figura 4) das plantas de arroz, evidenciando assim a maior fixação de carbono nos tecidos das plantas de arroz no período inicial de desenvolvimento da cultura. No entanto, ao final do ciclo não foi detectado efeito de dose de bispyribac-sodium, isolado ou em mistura, sobre o número de panículas e de colmos por metro linear. Observou-se ainda que a adição de clomazone resultou num acréscimo de $4 \mathrm{~cm}$ na altura das plantas de arroz (Figura 6).

Quanto ao rendimento de grãos, o incremento na dose de bispyribac-sodium mostrou resultados semelhantes à área foliar, com resultados positivos a partir das doses intermediárias. Estes resultados estão de acordo com Concenço et al. (2006b), que comprova que o efeito das plantas daninhas na cultura do arroz reduz a fitomassa seca e a altura de plantas. Resultados inferiores no controle de capim-arroz provocam redução no rendimento de grãos da cultura (Andrade, 1982; Andres \& Menezes, 1997; Balbinot Jr. et al., 2003).

Contrariando algumas expectativas, o atraso da água até a quarta época aumentou a área foliar (Figura 1) e a altura das plantas de arroz (Figura 5), quando na presença de clomazone. No entanto, esse comportamento não foi observado para fitomassa seca (Figura 3) e rendimento de grãos (Figura 9), demonstrando que, mesmo utilizando o herbicida clomazone, as plantas de arroz não foram favorecidas pelo atraso da irrigação, ocorrendo prejuízos na cultura. Esses resultados confirmam a recomendação de Ramirez et al. (2001) e Menezes \& Ramirez (2003) de antecipar a irrigação, com a justificativa de que com o atraso na irrigação as plantas de arroz perdem eficiência na formação de grãos, refletindo na produtividade da cultura.

$\mathrm{O}$ atraso na irrigação provocou aumento no número de colmos de capim-arroz para bispyribac-sodium isolado, causando redução do rendimento da cultura. Andres \& Menezes (1997) verificaram que cada planta de capimarroz presente em um metro quadrado de lavoura reduz a produtividade do arroz em $64 \mathrm{~kg} \mathrm{ha}^{-1}$. Com a adição do clomazone na mistura não se observou acréscimo no número de colmos de capim-arroz, verificando-se decréscimo no rendimento de grãos de arroz somente no atraso da entrada de água na lavoura, aos 32 dias após a emergência - arroz com quatro perfilhos.

O controle de capim-arroz para bispyribacsodium isolado reduziu linearmente com o atraso da água, enquanto a mistura reduziu o controle somente na quarta época de entrada de água, confirmando resultados de Brito et al. (2001) e Ramirez et al. (2001), que verificaram que a associação de bispyribac-sodium e clomazone proporcionou melhor controle de capim-arroz, estendendo a possibilidade de atraso na entrada de água, dentro de períodos razoáveis após a aplicação, pois diminui a possibilidade de reinfestação. Quando utilizado isoladamente, o herbicida bispyribac-sodium foi eficiente no controle de capim-arroz quando a irrigação se iniciou logo após a aplicação do produto nas três doses testadas (Figura 10), demonstrando assim a necessidade de lâmina de água para inibir a germinação das sementes de plantas daninhas, como enfatizado por Broch et al. (1997) e Gomes et al. (1999). Entretanto, observou-se que as doses menores, apesar de apresentarem niveis de capim-arroz 
semelhantes, mostraram diferenças quanto ao rendimento de grãos (Figura 10).

A avaliação visual de controle de capimarroz obtido em algumas situações (Figura 7) foi eficiente mesmo na época mais atrasada (aos 32 dias após a emergência - arroz com quatro perfilhos), embora com redução na eficiência de controle. Esses resultados estão de acordo com Brito et al. (2001) e Ramirez et al. (2001). Entretanto, cabe ressaltar que na época mais tardia observou-se redução no controle (maior número de colmos de capim por metro) (Figura 8) e, ainda, houve efeito negativo sobre o rendimento de grãos (Figura 9). Pode-se inferir ainda que em anos mais secos o efeito do retardamento poderá ser mais acentuado em função do estresse hídrico das plantas de arroz, associado ao efeito de competição das plantas daninhas sobre a cultura (Lauretti et al., 2001; Balbinot Jr. et al., 2003; Menezes \& Ramirez, 2003).

No controle químico de capim-arroz até três folhas, a adição de clomazone ao bispyribac-sodium permitiu a entrada de água na área até 15 dias após aplicação destes. O herbicida bispyribac-sodium foi eficiente para controle de capim-arroz, com três folhas, quando a entrada de água ocorreu até cinco dias após a aspersão e/ou até o perfilhamento do arroz irrigado, quando em mistura com clomazone. O desempenho das variáveis área foliar, altura de plantas, matéria seca da parte aérea, número de colmos e panículas das plantas de arroz é satisfatório com a entrada de água no estádio de quatro folhas do cultivar BRS Pelota quando se utilizou bispyribac-sodium, tanto isolado como em mistura com clomazone, quando a água é estabelecida no perfilhamento.

Subdoses de bispyribac-sodium são eficientes desde que a submersão seja imediata após a sua aplicação; esse herbicida. associado ao clomazone, é eficiente até o perfilhamento.

\section{LITERATURA CITADA}

ANDRES, A.; MENEZES, V. G. Controle de capim-arroz (Echinochloa crusgalli L. Beauv.) e angiquinho (Aeschynomene denticulata Benth.) com o herbicida bispyribac-sodium (bispyribac-sodium) em arroz irrigado. In: REUNIÃO DA CULTURA DO ARROZ IRRIGADO, 22., 1997. Balneário Camboriú. Anais... Itajaí: EPAGRI, 1997. p. 414-417.

Planta Daninha, Viçosa-MG v. 25, n. 4, p. 859-867, 2007
ANDRES, A.; MACHADO, S. L. O. Plantas daninhas em arroz irrigado. In: GOMES, A. S.; MAGALHÃES JR.; A. M. (Eds.) Arroz irrigado no sul do Brasil. Brasília: Embrapa Informação Tecnológica, 2004. p. 457-546.

ÁVILA, L. A. et al. Sistema de cultivo de arroz irrigado para o controle de arroz vermelho. Agropec. Clima Temperado, v. 3, p. 165-173, 2000.

BALBINOT Jr., A. A. et al. Características de plantas de arroz e a habilidade competitiva com plantas daninhas. Planta Daninha, v. 21, p. 165-174, 2003.

BRITO, G. G. et al. Avaliação da eficiência do herbicida bispyribac-sodium $400 \mathrm{SC}$ em mistura com clomazone no controle de plantas daninhas e seletividade à cultura do arroz (Oryza sativa L.) irrigado, em duas épocas de entrada de água. In: CONGRESSO BRASILEIRO DE ARROZ IRRIGADO, 2; REUNIÃO DA CULTURA DO ARROZ IRRIGADO, 24., 2001. Porto Alegre. Anais... Porto Alegre: Instituto Rio Grandense do Arroz, 2001. p. 539-541.

BROCH, D. L. et al. Influência da lâmina de água e de reguladores de crescimento no estabelecimento do arroz prégerminado. R. Bras. Agroc., v. 3, p. 51-57, 1997.

CONCENÇO, G. et al. Controle de plantas daninhas em arroz irrigado em função de doses de herbicidas préemergentes e início da irrigação. Planta Daninha, v. 24, p. 303-309, 2006a.

CONCENÇO, G. et al. Efeito de herbicidas aplicados em pré-emergência e momentos de início da irrigação no crescimento de plantas de arroz. Planta Daninha, v. 24, p. 295-301, 2006b.

EBERHARDT, D. S. Emergência e desenvolvimento inicial de arroz e de plantas daninhas em função da profundidade da semente e submersão do solo. In: REUNIÃO DA CULTURA DO ARROZ IRRIGADO, 22., 1997. Balneário Camboriú. Anais... Itajaí: EPAGRI, 1997. p. 387-390.

ERASMO, E. A. L.; PINHEIRO, L. L. A.; COSTA, N. V. Levantamento fitossocioló gico das comunidades de plantas infestantes em áreas de produção de arroz irrigado cultivado sob diferentes sistemas de manejo. Planta Daninha, v. 22, p. 195-201, 2004.

GOMES, A. S.; PAUletTo, E. A; PETRINI, J. A. Arroz irrigado: manejo de água. Pelotas: Embrapa Clima Temperado, 1999. 16 p. (Embrapa Clima Temperado. Circular Técnica, 16).

LAURETTI, R. L. B. et al. Efeitos de diferentes manejos de água no estabelecimento de plantas de arroz no sistema prégerminado. Pesq. Agropec. Bras., v. 36, p. 1093-1 099, 2001. 
MACHADO, S. L. O. et al. Consumo de água e perdas de nutrientes e de sedimentos na água de drenagem inicial do arroz irrigado. Ci. Rural, v. 36, p. 65-71, 2006.

MENEZES, V. G.; RAMIREZ, H. Rendimento de grãos de arroz irrigado em função do início da irrigação e do controle precoce de plantas daninhas em Cachoeirinha. In: CONGRESSO BRASILEIRO DE ARROZ IRRIGADO, 3. REUNIÃO DA CULTURA DO ARROZ IRRIGADO, 15. 2003. Balneário Camboriú. Anais... Itajaí: EPAGRI, 2003. p. 190-192.

NOLDIN, J. A. et al. Persistência do herbicida clomazone no solo e na água quando aplicado na cultura do arroz irrigado, sistema pré-germinado. Planta Daninha, v. 19, p. 401-408, 2001.

NOLDIN, J. A. et al. Produção agroecológica de arroz. Inf. Agropec., v. 25, p. 74-80, 2004.
RAMIREZ, H.; MENEZES, V. G.; MARIOT, C. H. P. Controle de capim-arroz com o herbicida bispyribac-sodium em mistura com clomazone na cultura do arroz irrigado. In: CONGRESSO BRASILEIRO DO ARROZ IRRIGADO, 2. REUNIÃO DA CULTURA DO ARROZ IRRIGADO, 24., 2001. Porto Alegre. Anais... Porto Alegre: Instituto Rio Grandense do Arroz, 2001. p. 528-530.

REDE OFICIAL DE LABORATÓRIOS DE ANÁLISE DE SOLO E DE TECIDO VEGETAL - ROLAS.

Recomendações de adubação e de calagem para os

Estados do Rio Grande do Sul e de Santa Catarina. 3.ed. Passo Fundo: SBCS-NRS, 1995. 223 p.

VIEIRA, R. F. et al. Aplicações seqüenciais de fomesafen via água de irrigação por aspersão no controle de Bidens pilosa . Planta Daninha, v. 24, p. 497-503, 2006. 